\title{
Complete infarct-related artery revascularization in acute myocardial infarction patients. CORAMI Registry
}

\author{
Zbigniew Siudak ${ }^{1}$, Blaz Mrevlje², Bogdan Januśs ${ }^{3}$, Artur Dziewierz ${ }^{4}$, Tomasz Rakowski ${ }^{4}$, Jacek Legutko ${ }^{4}$, \\ Stanisław Bartuś ${ }^{4}$, Dariusz Dudek ${ }^{1,4}$ \\ ${ }^{1}$ Department of Interventional Cardiology, Jagiellonian University Medical College, Krakow, Poland \\ ${ }^{2}$ University Heart Center Rostock, Rostock, Germany \\ ${ }^{3}$ Department of Interventional Cardiology, Municipal Hospital, Tarnow, Poland \\ ${ }^{4} 2^{\text {nd }}$ Department of Cardiology, Jagiellonian University Medical College, Krakow, Poland
}

Postep Kardiol Inter 2015; 11, 2 (40): 84-88

DOI: $10.5114 /$ pwki.2015.52279

\begin{abstract}
A bstract
Introduction: There are still limited data on the occurrence of multiple stenotic lesions within the infarct-related artery (IRA) in acute myocardial infarction (MI), and there is no consensus on the optimal treatment of this patient subgroup, which varies between centers and operators.

Aim: To analyse the clinical efficacy of percutaneous coronary intervention $(\mathrm{PCl})$ strategy of culprit lesion only in patients with myocardial infarction.

Material and methods: Patients with acute MI with the presence of at least two significant lesions in the IRA - (1) the target culprit lesion which required immediate stenting (> 50-100\% stenosis) and (2) a second distal critical lesion (70-90\%) - were included in the registry. Both lesions in the IRA were considered to be independent lesions requiring two separate stent platforms to be covered (no overlap). The decision on the treatment strategy of either complete (CR) or culprit-lesion-only (CLO) revascularization was at the discretion of the operator.

Results: There were altogether 95 patients enrolled in the registry, 63 (66\%) in the group with CR of the IRA and 32 (34\%) with CLO revascularization, which did not differ in terms of baseline demographics. In-hospital and long-term outcomes were similar between the groups. Stent thrombosis at 1 year occurred in $1.6 \%$ in CR and in $6.2 \%$ in CLO groups respectively (statistically not significant). There were no patients from the CLO group who had a planned percutaneous coronary intervention (PCI) of the $2^{\text {nd }}$ lesion in the IRA during 1-year observation.

Conclusions: At 1 year the clinical outcome was similar between those with complete and CLO PCI. Complete coverage of significant lesions did not increase the risk of stent thrombosis or need for repeated revascularization in long-term observation.
\end{abstract}

Key words: myocardial infarction, revascularization, stent, registry.

\section{Introduction}

Concomitant significant stenosis in coronary arteries other than the infarct-related artery (IRA) occurs in $40 \%$ to $60 \%$ of patients undergoing primary percutaneous coronary intervention (PPCI) for ST-elevation myocardial infarction (STEMI) both in historic and recent data [1-7]. Moreover, the presence of multivessel coronary artery disease in the STEMI setting is usually associated with adverse long-term outcome [1, 3, 5-8]. According to the current European Society of Cardiology (ESC) revascularization guidelines, $\mathrm{PCl}$ of only culprit vessel should be performed in STEMI, with an exception of cardiogenic shock (Ila), whereas immediate $\mathrm{PCl}$ of all lesions during
$\mathrm{PPCl}$ may only be considered in selected patients (IIb) [9]. Similarly, the mode of revascularization in non-ST elevation myocardial infarction (NSTEMI) should be decided taking into account comorbidities, clinical data and extent of the atherosclerotic disease. There are multiple data from meta-analyses, randomized trials and registries which either support complete revascularization in acute myocardial infarction [10-14] or support a more conservative guideline-recommended approach [15-18].

However, there are still limited data on the occurrence of multiple stenotic lesions within the IRA in a STEMI and NSTEMI setting. At the same time there is no consensus on the optimal treatment of this patient subgroup. The

\section{Corresponding author:}

Zbigniew Siudak MD, PhD, Department of Interventional Cardiology, Jagiellonian University Medical College, 17 Kopernika St, $31-501$ Krakow, Poland, phone: + 481242471 81, fax: + 481242471 84, e-mail: zbigniew.siudak@gmail.com

Received: 19.11.2014, accepted: 3.03.2015. 
strategies vary between centers but also $\mathrm{PCl}$ operators. Scarce data suggest that "spot" only coverage of stenotic lesions with minimization of stent length might be superior to the "full metal jacket" strategy at least in a group of stable angina patients $[19,20]$. It was also confirmed that the length and number of implanted drug eluting stents (DES) is associated with increased risk of stent thrombosis [21, 22].

\section{Aim}

The aim of the CORAMI registry was to assess the contemporary treatment strategies in acute myocardial infarction patients with multiple stenotic lesions in the IRA with either complete (CR) or culprit-lesion-only (CLO) revascularization and its influence on long-term outcome.

\section{Material and methods}

The CORAMI Registry was first planned as a randomized clinical trial (NCT01218815). The study was launched in Polish and Slovenian sites, but due to difficulties with enrollment the study was terminated. The investigators decided that it would be worth continuing the research, so the CORAMI Registry was started instead.

The CORAMI Registry was a prospective, international (Poland, Slovenia), multicenter (6 sites in Poland, 1 in Slovenia) observational study which was performed in experienced invasive cardiology centers with 24/7 PCI duty with patient enrollment between October 2011 and June 2012.

Patients with STEMI or NSTEMI over 18 years old with the presence of at least two significant lesions in the IRA - (1) the target culprit lesion which required immediate stenting (> 50-100\% stenosis) and (2) a second distal critical lesion (70-90\%) - were included in the registry. Both lesions in the IRA were considered to be independent lesions requiring two separate stent platforms to be covered (no overlap). The decision on the treatment strategy of either CR or CLO revascularization was at the discretion of the $\mathrm{PCl}$ operator. Further pharmacological treatment was according to local standards and best clinical practice. Patient follow-up phone calls and/or ambulatory visits were performed at 12 months after the enrollment.

The primary end-point of this analysis were: overall mortality at 1 year, confirmed stent thrombosis at 12 months according to the Academic Research Consortium (ARC) definition, repeated myocardial infarction at 12 months, urgent target vessel revascularization (TVR) at 12 months and planned TVR (PCI or CABG) at 12 months. Secondary clinical endpoints included: immediate in-hospital angiographic complications (at least one or more of the following: distal embolisation, no-reflow, slow-flow, acute coronary artery occlusion, artery perforation, tamponade, dissection type $B$ and above), urgent in-hospital TVR ( $\mathrm{PCl}$ and/or CABG), complete radiation dose in $\mathrm{mGy}$.
The CORAMI Registry complied with the Declaration of Helsinki and was approved by the Bioethics Committee at the Jagiellonian University in Krakow, Poland (KBET/140/L/2010 of October $7^{\text {th }}, 2010$ ).

\section{Statistical analysis}

Data were analyzed according to the established statistical standards. Categorical variables were presented with counts and as percentages and continuous variables as means ( \pm standard deviation). Differences between groups were tested using Fisher's exact test or Pearson's $\chi^{2}$ test for categorical variables and the Mann-Whitney $U$ test for continuous variables. Values of $p$ less than 0.05 were considered statistically significant. Two-sided tests were applied. All calculations were done with JMP 9.0.0 software by an experienced statistician.

\section{Results}

There were altogether 95 patients enrolled in the registry, $63(66 \%)$ in the group with complete revascularization of the IRA and 32 (34\%) with CLO revascularization. Baseline demographics and procedural aspects are presented in Table I. The balance of STEMI diagnosis was similar between the groups (CR vs. CLO 73\% vs. 84\%, $p=0.305)$. In-hospital and long-term outcome as well as adherence to dual antiplatelet therapy are presented in Table II. There were no patients from the CLO group who had a planned $\mathrm{PCl}$ of the $2^{\text {nd }}$ lesion in the IRA during 1-year observation.

\section{Discussion}

The CORAMI Registry is one of the first studies scheduled to evaluate the impact of complete infarct artery revascularization in patients who are treated with coronary angioplasty with stenting during the acute phase of STEMI and NSTEMI. The incidence of two independent stenotic lesions in the IRA is a rare situation (3\% in our population, data not shown) but certainly requires scientific evaluation as there are no clear guidelines on how to intervene, especially in a myocardial infarction setting [9]. Therefore, these decisions are often based on coronary anatomy, patient clinical status and empirical experience of a single $\mathrm{PCl}$ operator including thrombolysis in myocardial infarction (TIMI) flow after initial lesion stenting, presence of hemodynamic compromise, location of the distal lesion as well as artery diameter. In the CORAMI study patients with two lesions identified in the IRA were analyzed. The first lesion was treated as the culprit one, which was always stented, and the other was treated with a stent based on the discretion of the $\mathrm{PCl}$ operator but had to be less than $90 \%$ in diameter stenosis (we did not want to include patients with obvious flow limiting critical lesions > 90\%, which should be stented during the index procedure). Our early assumption that most such patients will receive multiple stents to cover all le- 
Table I. Baseline characteristics, angiography and $\mathrm{PCl}$

\begin{tabular}{|c|c|c|c|}
\hline Variable & CR & CLO & Value of $p$ \\
\hline No. of patients & $66 \%(63)$ & $34 \%(32)$ & - \\
\hline Age & $66.3 \pm 11.3$ & $69.7 \pm 11.9$ & 0.182 \\
\hline Gender (male) & $75 \%(47)$ & $75 \%(25)$ & 0.966 \\
\hline $\mathrm{BMI}\left[\mathrm{kg} / \mathrm{m}^{2}\right]$ & $27.5 \pm 3.4$ & $27.1 \pm 3.1$ & 0.518 \\
\hline $\begin{array}{l}\text { Previous myocardial } \\
\text { infarction }\end{array}$ & $11 \%(7)$ & $9 \%(3)$ & 0.794 \\
\hline Arterial hypertension & $63.5 \%(40)$ & $62.5 \%(20)$ & 0.912 \\
\hline Hyperlipidemia & $40 \%(25)$ & $31 \%(10)$ & 0.546 \\
\hline Diabetes mellitus & $16 \%(10)$ & $12.5 \%(4)$ & 0.767 \\
\hline Chronic kidney disease & $3 \%(2)$ & $3 \%(1)$ & 0.989 \\
\hline Previous stroke & $1.6 \%(1)$ & ०\% (0) & 0.473 \\
\hline Previous PCl & $6 \%(4)$ & $3 \%(1)$ & 0.613 \\
\hline Previous CABG & $1.6 \%(1)$ & $0 \%(0)$ & 0.473 \\
\hline Smoking & $59 \%(37)$ & $37.5 \%(12)$ & 0.262 \\
\hline \multicolumn{4}{|c|}{ Clinical status on admission: } \\
\hline$H R$ & $77.3 \pm 19.5$ & $75.8 \pm 13.6$ & 0.971 \\
\hline SBP & $141 \pm 26$ & $131 \pm 21$ & 0.075 \\
\hline DBP & $81 \pm 17$ & $76 \pm 11$ & 0.042 \\
\hline \multicolumn{4}{|c|}{ Number of critically stenosed arteries: } \\
\hline $\begin{array}{l}\text { 1-vessel disease (IRA } \\
\text { only) }\end{array}$ & $35 \%(22)$ & $31 \%(10)$ & 0.820 \\
\hline Multivessel disease & $65 \%(41)$ & $69 \%(22)$ & \\
\hline \multicolumn{4}{|l|}{ Infarct-related artery (IRA): } \\
\hline LAD & $25 \%(16)$ & $41 \%(13)$ & 0.269 \\
\hline$C x$ & $8 \%(5)$ & $9 \%(3)$ & \\
\hline RCA & $67 \%(42)$ & $50 \%(16)$ & \\
\hline \multicolumn{4}{|l|}{ TIMI before $\mathrm{PCl}$ : } \\
\hline 0 & $41 \%(26)$ & $56 \%(18)$ & 0.407 \\
\hline 1 & $14 \%(9)$ & $16 \%(5)$ & \\
\hline 2 & $21 \%(13)$ & $9 \%(3)$ & \\
\hline 3 & $24 \%(15)$ & $19 \%(6)$ & \\
\hline \multicolumn{4}{|l|}{ Number of stents in IRA: } \\
\hline$\geq 2$ stents in IRA & $100 \%(63)$ & $0 \%(0)$ & $<0.001$ \\
\hline 1 stent in IRA & $0 \%(0)$ & $100 \%(32)$ & \\
\hline No stents in IRA & $0 \%(0)$ & $0 \%(0)$ & \\
\hline \multicolumn{4}{|l|}{ Type of stent: } \\
\hline DES & $44 \%(28)$ & $34 \%(11)$ & 0.385 \\
\hline $\mathrm{PCI}$ procedure time [min] & $33.0 \pm 21.7$ & $26.6 \pm 18.1$ & 0.092 \\
\hline Radiation [mGy] & $1406 \pm 921$ & $1171 \pm 1250$ & 0.055 \\
\hline $\operatorname{LVEF}(\%)$ & $53.2 \pm 10.9$ & $51.5 \pm 12.3$ & 0.566 \\
\hline $1^{\text {st }}$ stent diameter [mm] & $3.2 \pm 0.4$ & $3.2 \pm 0.4$ & 0.824 \\
\hline $1^{\text {st }}$ stent length [mm] & $20.5 \pm 7.3$ & $21.1 \pm 7.4$ & 0.737 \\
\hline $2^{\text {nd }}$ stent diameter $[\mathrm{mm}]$ & $3.2 \pm 0.5$ & - & - \\
\hline $2^{\text {nd }}$ stent length $[\mathrm{mm}]$ & $20.2 \pm 7.9$ & - & - \\
\hline TIMI 3 flow after PCI & $95 \%(60)$ & $91 \%(29)$ & 0.401 \\
\hline Thrombectomy & $25 \%(16)$ & $37.5 \%(12)$ & 0.242 \\
\hline
\end{tabular}

Table II. Primary and secondary clinical endpoints and adherence to DAPT

\begin{tabular}{lccc} 
Variable & CR & CLO & Value of $p$ \\
\hline No. of patients & $66 \%(63)$ & $34 \%(32)$ & - \\
\hline 12 months observation: & & & \\
\hline Death & $6.4 \%(4)$ & $9.4 \%(3)$ & 0.593 \\
\hline Stent thrombosis & $1.6 \%(1)$ & $6.2 \%(2)$ & 0.219 \\
\hline Acute MI & $1.6 \%(1)$ & $3.1 \%(1)$ & 0.622 \\
\hline Urgent TVR & $4.8 \%(3)$ & $9.4 \%(3)$ & 0.383 \\
\hline Planned TVR & $0 \%(0)$ & $0 \%(0)$ & - \\
\hline In-hospital events: & & & \\
\hline Death & $1.6 \%(1)$ & $6.2 \%(2)$ & 0.219 \\
\hline Stent thrombosis & $1.6 \%(1)$ & $6.2 \%(2)$ & 0.219 \\
\hline Angiographic & $1.6 \%(1)$ & $3.1 \%(1)$ & 0.622 \\
\hline complications* & & & \\
\hline Urgent TVR (PCl or CABG) & $1.6 \%(1)$ & $6.2 \%(2)$ & 0.219 \\
\hline DAPT at 12 months: & & & \\
\hline Clopidogrel & $47.6 \%(30)$ & $34 \%(11)$ & 0.452 \\
\hline Prasugrel & $1.6 \%(1)$ & $6.2 \%(2)$ & \\
\hline Ticagrelor & $4.8 \%(3)$ & $6.2 \%(2)$ & \\
\hline ASA only & $46 \%(29)$ & $53.6 \%(17)$ & \\
\hline
\end{tabular}

*Defined as at least one or more of the following: distal embolisation, no-reflow, slow-flow, acute coronary artery occlusion, artery perforation, tamponade, dissection type B and above. DAPT - dual antiplatelet therapy, ASA - acetylsalicylic acid, TVR - target vessel revascularization, $P C I$ - percutaneous coronary intervention, $C A B G$ - coronary artery bypass graft, $\mathrm{MI}$ - myocardial infarction.

sions turned out to be at least exaggerated. In as many as $34 \%$ of STEMI and NSTEMI cases the second distal lesion in the IRA was left without stenting and intended for conservative treatment. During a 12-month follow-up none of the $2^{\text {nd }}$ lesions in the CLO group were scheduled for an elective PCl. Elective PCls of non-target vessel lesions were performed equally between study groups in follow-up since ca. 2/3 of study patients had multivessel disease diagnosed in baseline angiography.

The benefit of the CLO strategy in STEMI and NSTEMI during in-hospital stay was observed for decreased overall $\mathrm{PCl}$ time and lower radiation exposure for the patient, but was only borderline in terms of statistical inference. Even though the mean length of the implanted scaffold in the CR group was ca. $41 \mathrm{~mm}$ vs. $21 \mathrm{~mm}$, the immediate $\mathrm{PCl}$ outcome in both groups was similar (a rate of TIMI 3 flow). Periprocedural complications as defined by the protocol were rare in both groups. Both during in-hospital and 12-month observation the occurrence of death, stent thrombosis and urgent TVR was more frequently observed in the CLO group, but due to low sample size it was not statistically significant. Thus we need to conclude that in the CORAMI patient sample there was no benefit from complete IRA revascularization at least in terms of occurrence of clinical endpoints in longer observation. Contrary to some reports, there was no excess of stent thrombosis with more stents implanted [21, 22]. It is also interesting to observe that as many as half of patients in the CORAMI registry did not take dual antiplate- 
let therapy any longer at 12 months. The CORAMI study raises a number of issues that would ideally be answered in a larger randomized study.

This was a registry study with low sample size, and drawing definite conclusions based on the results of CORAMI should be cautious. There was no independent angiographic core lab evaluation of $\mathrm{PCl}$ procedures and procedural complications. The follow-up observation was mainly performed by telephone calls. In addition, the results cannot be applied to patients treated with new stents designs (i.e. mesh covered stents, self-expandable stents) or bioresorbable vascular scaffold implantation during primary $\mathrm{PCI}$ for STEMI $[23,24]$.

\section{Conclusions}

Complete infarct-related artery revascularization in acute myocardial infarction was performed in two-thirds of patients in the CORAMI Registry. At 1 year the clinical outcome was similar between those with complete and CLO PCl. Complete coverage of significant lesions did not increase the risk of stent thrombosis or need for repeated revascularization in long-term observation.

\section{Acknowledgments}

We would like to thank the Krakow Cardiovascular Research Institute (KCRI) and Kamil Fijorek MSc for professional data management and statistical analysis.

\section{Conflict of interest}

The authors declare no conflict of interest.

\section{References}

1. Jaski BE, Cohen JD, Trausch J, et al. Outcome of urgent percutaneous trans-luminal coronary angioplasty in acute myocardial infarction: comparison of single-vessel versus multivessel coronary artery disease. Am Heart J 1992; 124: 1427-33.

2. Moreno R, Garcia E, Elizaga J, et al. Results of primary angioplasty in patients with multivessel disease. Rev Esp Cardiol 1998; 51: 547-55.

3. Sorajja P, Gersh BJ, Cox DA, et al. Impact of multivessel disease on reperfusion success and clinical outcomes in patients undergoing primary percutaneous coronary intervention for acute myocardial infarction. Eur Heart J 2007; 28: 1709-16.

4. Xu F, Chen YG, Li JF, et al. Multivessel percutaneous coronary intervention in Chinese patients with acute myocardial infarction and simple nonculprit arteries. Am J Med Sci 2007; 333: 376-80.

5. Hanratty CG, Koyama Y, Rasmussen HH, et al. Exaggeration of nonculprit stenosis severity during acute myocardial infarction: implications for immediate multivessel revascularization. J Am Coll Cardiol 2002; 40: 911-6.

6. van der Schaaf RJ, Vis MM, Sjauw KD, et al. Impact of multivessel coronary disease on long-term mortality in patients with ST-elevation myocardial infarction is due to the presence of a chronic total occlusion. Am J Cardiol 2006; 98: 1165-9.

7. Dziewierz A, Siudak Z, Rakowski T, et al. Impact of multivessel coronary artery disease and noninfarct-related artery revascu- larization on outcome of patients with ST-elevation myocardial infarction transferred for primary percutaneous coronary intervention (from the EUROTRANSFER Registry). Am I Cardiol 2010; 106: 342-7.

8. Kalarus Z, Lenarczyk R, Kowalczyk J, et al. Importance of complete revascularization in patients with acute myocardial infarction treated with percutaneous coronary intervention. Am Heart J 2007; 153: 304-12.

9. Windecker S, Kolh P, Alfonso F, et al. 2014 ESC/EACTS Guidelines on myocardial revascularization: The Task Force on Myocardial Revascularization of the European Society of Cardiology (ESC) and the European Association for Cardio-Thoracic Surgery (EACTS) Developed with the special contribution of the European Association of Percutaneous Cardiovascular Interventions (EAPCI). Eurolntervention 2015; 10: 1024-94.

10. Jo HS, Park JS, Sohn JW, et al. Culprit-lesion-only versus multivessel revascularization using drug-eluting stents in patients with ST-segment elevation myocardial infarction: a Korean acute myocardial infarction registry-based analysis. Korean Circ J 2011; 41: 718-25.

11. Politi L, Sgura F, Rossi R, et al. A randomised trial of target-vessel versus multi-vessel revascularisation in ST-elevation myocardial infarction: major adverse cardiac events during long-term follow-up. Heart 2010; 96: 662-7.

12. Varani E, Balducelli M, Aquilina M, et al. Single or multivessel percutaneous coronary intervention in ST-elevation myocardial infarction patients. Catheter Cardiovasc Interv 2008; 72: 927-33.

13. Jeger R, Jaguszewski M, Nallamothu BN, et al. Acute multivessel revascularization improves 1-year outcome in ST-elevation myocardial infarction: a nationwide study cohort from the AMIS Plus registry. Int J Cardiol 2014; 172: 76-81.

14. Wald DS, Morris JK, Wald NJ, et al. Randomized trial of preventive angioplasty in myocardial infarction. N Engl J Med 2013; 369: 1115-23.

15. Manari A, Varani E, Guastaroba P, et al. Long-term outcome in patients with ST segment elevation myocardial infarction and multivessel disease treated with culprit-only, immediate, or staged multivessel percutaneous revascularization strategies: insights from the REAL registry. Catheter Cardiovasc Interv 2014; 84: 912-22.

16. Sethi A, Bahekar A, Bhuriya R, et al. Complete versus culprit only revascularization in acute ST elevation myocardial infarction: a meta-analysis. Catheter Cardiovasc Interv 2011; 77: 163-70.

17. Vlaar PJ, Mahmoud KD, Holmes DR Jr, et al. Culprit vessel only versus multivessel and staged percutaneous coronary intervention for multivessel disease in patients presenting with ST-segment elevation myocardial infarction: a pairwise and network meta-analysis. J Am Coll Cardiol 2011; 58: 692-703.

18. Kornowski R, Mehran R, Dangas G, et al. Prognostic impact of staged versus "one-time" multivessel percutaneous intervention in acute myocardial infarction: analysis from the HORIZONS-AMI (harmonizing outcomes with revascularization and stents in acute myocardial infarction) trial. J Am Coll Cardiol 2011; 58: 704-11.

19. Kim S, Yun KH, Kang WC, et al. Comparison of full lesion coverage versus spot drug-eluting stent implantation for coronary artery stenoses. Yonsei Med J 2014; 55: 584-91.

20. Katritsis DG, Korovesis S, Tzanalaridou E, et al. Comparison of long versus short ("spot") drug-eluting stenting for long coronary stenoses. Am J Cardiol 2009; 104: 786-90. 
21. Chieffo A, Bonizzoni E, Orlic D, et al. Intraprocedural stent thrombosis during implantation of sirolimus-eluting stents. Circulation 2004; 109: 2732-6.

22. Pinto Slottow TL, Steinberg DH, Roy PK, et al. Observations and outcomes of definite and probable drug-eluting stent thrombosis seen at a single hospital in a four-year period. Am J Cardiol 2008; 102: 298-303.

23. Dudek D, Dziewierz A, Kleczynski P, et al. Long-term follow-up of mesh-covered stent implantation in patients with ST-segment elevation myocardial infarction. Kardiol Pol 2014; 72: 140-5.

24. Dudek D, Rzeszutko L, Zasada W, et al. Bioresorbable vascular scaffolds in patients with acute coronary syndromes: POLAR ACS study. Pol Arch Med Wewn 2014; 124: 669-77. 